\title{
Interferon regulatory factor 4 binding protein is a novel p53 target gene and suppresses cisplatin- induced apoptosis of breast cancer cells
}

\author{
Mingzhen Yang ${ }^{1}$, Fang Yuan ${ }^{2,3}$, Peng $\mathrm{Li}^{1}$, Zhongjiao Chen ${ }^{1}$, An Chen ${ }^{1}$, Shuhui $\mathrm{Li}^{1}$ and Chuanmin $\mathrm{Hu}^{1 *}$
}

\begin{abstract}
Background: Our previous work demonstrated that ectopic expression of interferon regulatory factor 4 binding protein (IBP) was correlated with the malignant behaviour of human breast cancer cells. The mechanisms controlling differential expression of IBP in breast cancer still remain unknown.

Results: To investigate the mechanism of IBP dysregulation in breast cancer, we identified IBP was a novel p53 target gene. IBP expression was negatively regulated by wild-type p53 and was p53 dependently suppressed by DNA damage agent cisplatin. Furthermore, high levels of IBP were found to decrease cisplatin-induced growth suppression and apoptotic cell death, which was associated with decreased p53 activity and imbalanced Bcl-2 family member expression.

Conclusions: IBP is a novel p53 target gene which suppresses cisplatin-mediated apoptosis of breast cancer cells via negative feedback regulation of the p53 signalling pathway, suggesting IBP may serve as a target for pharmacologic intervention of breast cancer resistant to cisplatin therapy.
\end{abstract}

Keywords: Breast cancer, Interferon regulatory factor 4 binding protein (IBP), p53, Cisplatin, Apoptosis

\section{Background}

Since its discovery over 30 years ago, p53 has been shown to play a key role in mediating cell responses to stress. p53 primarily accomplishes this by inducing or repressing a number of genes involved in cell cycle arrest, senescence, apoptosis, DNA repair, and angiogenesis [1]. Among the roles of p53, its tumor-suppression activity is associated with its ability to function as a transcriptional master regulator [2]. The identification of additional p53 target genes is steadily progressing and may elucidate the mechanisms by which p53 exerts its tumour-suppression activity.

Breast cancer is the most frequent cancer in women. An estimated 1.15 million new cases of breast cancer were identified in 2002. In China, breast cancer registries record annual incidence increases of $3 \%$ to $4 \%$ [3]. Genetic studies have revealed that at least one third of nonfamilial breast cancers contain mutations in p53 [4], and

\footnotetext{
* Correspondence: chuminhu@163.com

${ }^{1}$ Department of Clinical Biochemistry, Third Military Medical University,

Chongqing 400038, P.R. China

Full list of author information is available at the end of the article
}

1,400 p53 mutations have been identified in breast cancer [5]. Efficacy of p53 activity represents a vulnerable link in the barriers to tumorigenesis in the breast epithelium [6]. In addition to its role in tumorigenesis, p53 also affects the effect of platinum therapy [7]. Previous studies have shown that the p53 pathway is inactivated in cisplatin-resistant MCF-7 breast cancer cells [8].

The Interferon regulatory factor 4 binding protein (IBP) gene (NM_022047), also known as DEF6 or SLAT, has been mapped to human chromosome 6p21.31 and is centromeric to the MHC locus [9]. IBP is broadly expressed in immune cells and can be detected in both T- and B-cell compartments. In the immune system, IBP functions as a guanine nucleotide exchange factor (GEF), which is an upstream activator of the Rho-family GTPases activates the Rac1, RhoA and CDC42 GTPases [10,11], modulates TCR-induced signalling events [12], and regulates TLR4-mediated signalling [13]. Loss of IBP in mice led to the spontaneous development of systemic autoimmunity [14]. Studies have shown that IBP has functions in other systems. IBP is expressed in muscle cells and influences myoblast differentiation [11]. It is one of the top five 
genes that distinguish extraskeletal myxoid chondrosarcoma (EMC) from other sarcomas [15]. Our laboratory reported that IBP was over-expressed in a considerable proportion of human breast and colorectal cancers $[16,17]$. IBP and p53 protein levels were negatively correlated among 107 breast cancer tissue samples [16]. The expression pattern of IBP, its transcriptional regulation, and especially the link between IBP and p53 in breast cancer are poorly understood.

In the present study, we sought to better understand the mechanisms controlling differential expression of IBP. We found that IBP contains a noncanonical p53-binding site in its $5^{\prime}$-flanking region. IBP expression was suppressed when wild-type p53 was directly bound to IBP promoter. Further, IBP was down-regulated by the DNA damage agents in breast cancer cell lines. Breast cancer cells overexpressing IBP were resistant to cisplatin-induced growth suppression and apoptosis. IBP knockdown increased cisplatin chemosensitivity and up-regulated p53 expression. Our results demonstrate that IBP is a novel p53 target gene which suppresses cisplatin-mediated apoptosis of breast cancer cells via negative feedback regulation of the p53 signaling pathway.

\section{Results}

\section{p53 inhibits the transcriptional activity of the IBP}

\section{promoter}

To investigate transcriptional regulation of IBP, we first analyzed the 5 '-flanking region of IBP gene. PROMO bioinformatics analysis (http://alggen.lsi.upc.edu/) [18,19] demonstrated that it contained two p53 binding sequences: -231 to -225 (GGGCCTC) and -223 to -217 (CATG $\mathrm{CCC}$ ). The canonical p53-binding site was originally defined as RRRCWWGYYY and contained a separation of 0 to $13 \mathrm{bp}$, where $\mathrm{R}=$ purine, $\mathrm{Y}=$ pyrimidine, and $\mathrm{W}=\mathrm{A}$ or $\mathrm{T}$ [20]. The noncanonical sequences were composed of $3 / 4$ or $1 / 2$ sites that are functional targets for $\mathrm{p} 53$ transactivation [2,21]. As shown in Figure 1A, the IBP gene -231 to -217 contained a putative noncanonical p53-binding site with a $1 / 2$ site. To examine whether the putative IBP p53binding site was functionally responsible for $\mathrm{p} 53$-dependent transcription, we subcloned 5 -deletion mutants of the IBP 5 '-flanking region into a luciferase expression vector pGL3basic, and fragment pIV $(-294$ to +60$)$, which has the strongest transcriptional activity (Figure 1B) and harbours p53-binding site, was transiently transfected into HCT116 p53 $3^{-/}$or HCT116 $\mathrm{p}^{+/+}$(wild-type p53) cells. pIV exhibited higher luciferase activity in p53 knockout HCT116 cells (Figure 1C). When pIV or pV was co-transfected with an empty pCMV, pCMV-p53 or pCMV-p53R175H vector into p53 null HCT116 cells, pCMV-p53 significantly decreased the luciferase activity of pIV. pCMV-p53R175H, which expressed a p53 mutant, did not affect pIV luciferase activity (Figure 1D). Additionally, we infected HCT116 p53 ${ }^{-/-}$cells with Ad-p53 at increasing concentrations. pIV exhibited a dose dependent luciferase activity decrease in response to increased Ad-p53, while $\mathrm{pV}$ did not. And when the putative p53-binding site (-231/-217) was deleted from pIV, Ad-p53 did not significantly decrease the luciferase activity (Figure $1 \mathrm{E}$ ). These observations indicate that functional p53 decreases the activity of the IBP promoter through its putative p53-binding site.

\section{p53 attenuates IBP expression}

To further test whether p53 decreases IBP expression, MCF-7 cells (wild-type p53) were infected with Ad-p53 or Ad-GFP (as a control). After $96 \mathrm{~h}$ IBP protein was significantly decreased with increased p53 expression (Figure 2A). To determine the effects of endogenous p53 on IBP expression, we treated MCF-7 cells with MDM2 antagonist Nutlin-3 [22] for $8 \mathrm{~h}$. The IBP protein level was dose-dependently attenuated (Figure 2B). And in p53 null HCT116 cells, Nutlin-3 could not decrease IBP expression (see Additional file 1). To determine whether p53 was required for IBP suppression, p53-targeting RNAi lentiviral particles and the p53 inhibitor pifithrin$\alpha$ [23] were used in MCF-7 cells. The knockdown of p53 in MCF-7 cells increased IBP expression (Figure 2C), and an increased IBP protein expression was observed with increasing doses of pifithrin- $\alpha$ (Figure 2D). p21, which is a p53-responsive gene [24], was used as an internal control in these experiments. To test whether p53 regulates transcriptional level of IBP, quantitative RTPCR was performed. As shown in Figure 2E, Ad-p53 and Nutlin- 3 decreased IBP expression, while pifithrin- $\alpha$ and p53-targeting RNAi lentiviral particles increased IBP expression. These results indicate that IBP expression is directly associated with p53 activation and thus is a p53responsive gene.

\section{p53 protein binds to IBP core promoter}

To further investigate the ability of p53 to bind the putative p53-binding site, 30-bp oligonucleotides that were complementary to the p53-binding site were synthesised, and EMSA was performed using MCF-7 cell nuclear extracts. Nuclear proteins from HCT116 $\mathrm{p} 53^{-/-}$were extracted as a negative control. Specific binding was

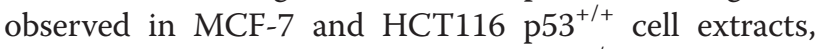
but it did not occur in the HCT116 $\mathrm{p} 53^{-/-}$extracts. Unlabelled oligonucleotides that were derived from the p53 consensus binding sites of p21 effectively competed with the labelled IBP probe and vice versa. Addition of a p53 antibody to the reaction resulted in a supershift of the labelled bands (Figure 3A). These results demonstrate that p53 specifically binds to p53-binding site of the IBP promoter in vitro.

Because p53 protein is able to bind to the IBP promoter in vitro, we tested whether p53 can also bind to 
A

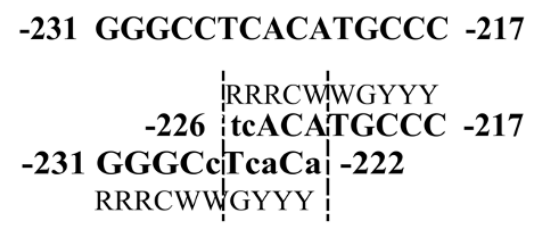

B

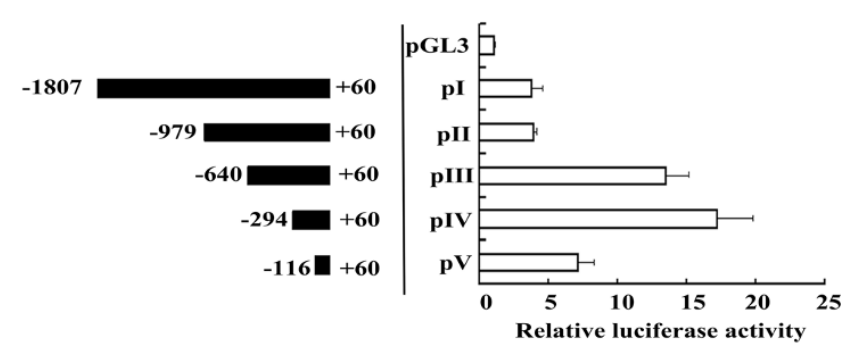

C

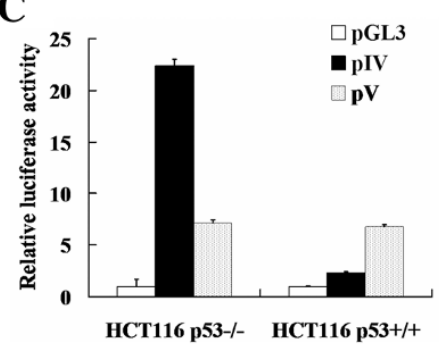

D

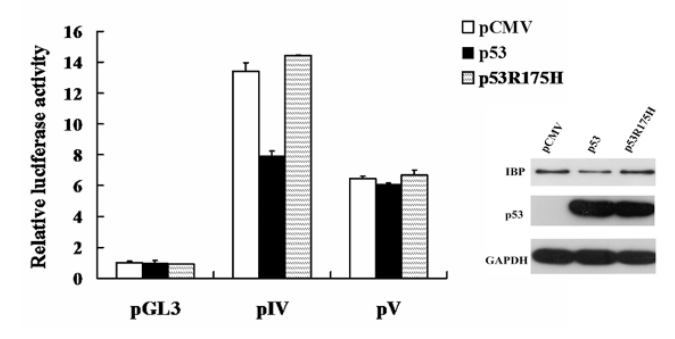

$\square$ Ad-p53 -

$\square$ Ad-p53 +

$\square$ Ad-p53 ++

囲 Ad-p53 +++

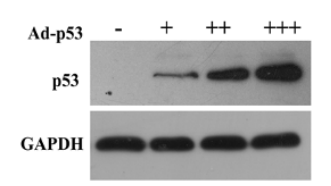

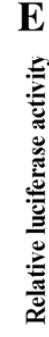
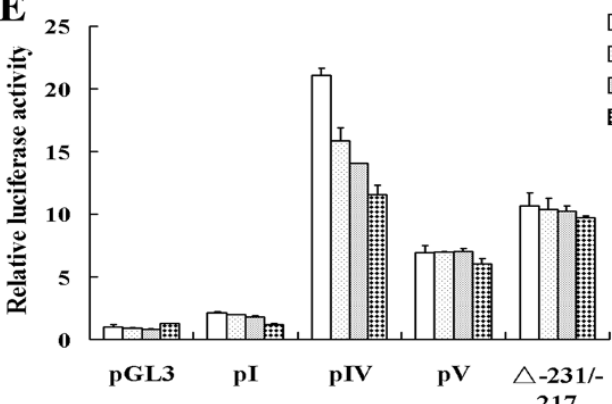

217

Figure 1 p53 inhibits the transcriptional activity of the IBP promoter. (A) The putative p53-binding site that is located in the promoter region of the IBP gene is shown. The -231 to -222 and -226 to -217 regions contain noncanonical $1 / 2$ sites. (B) Schematic representations of the five promoter-reporter constructs that contained different-length fragments that were cloned into pGL3-basic vector are shown. The promoter-luciferase constructs or the promoterless vector was transiently transfected into HEK293 cells. The luciferase activity was normalised to Renilla luciferase activity that was expressed by pRL-TK and is presented as the mean \pm SD of triplicate experiments. (C) HCT116 p53 $3^{-/-}$and

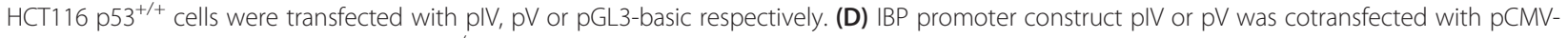
p53 or pCMV-p53R175H into HCT116 p53--- cells. The cotransfection with the empty pCMV vector serves as a control. The right inset shows the

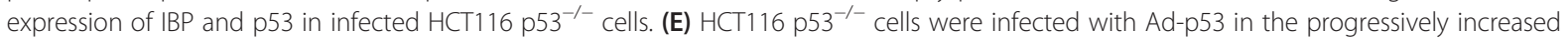
concentration. $\left(+, 10^{2} ;++, 10^{4} ;+++, 10^{6}\right.$ plague-forming units). The right inset shows the expression of p53 in infected HCT116 p53 ${ }^{-/-}$cells. Cells were transfected with the IBP promoter constructs (pl, pIV, pV or $-231 /-217$ deleted pIV).

the IBP promoter in native cellular chromatin. ChIP was performed with a p53 antibody to precipitate chromatin from doxorubicin treated MCF-7, HCT116 $\mathrm{p} 53^{-1-}$ and

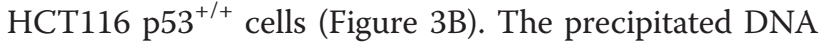
was PCR-amplified using primers that flanked the p53- binding site in the IBP promoter, to produce an expected

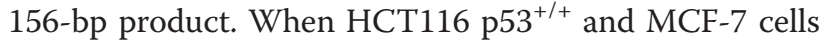
were treated with $50 \mathrm{nmol} / \mathrm{L}$ doxorubicin, the amplified band was increased. This result demonstrates that p53 protein also binds to the IBP promoter p53-binding site 

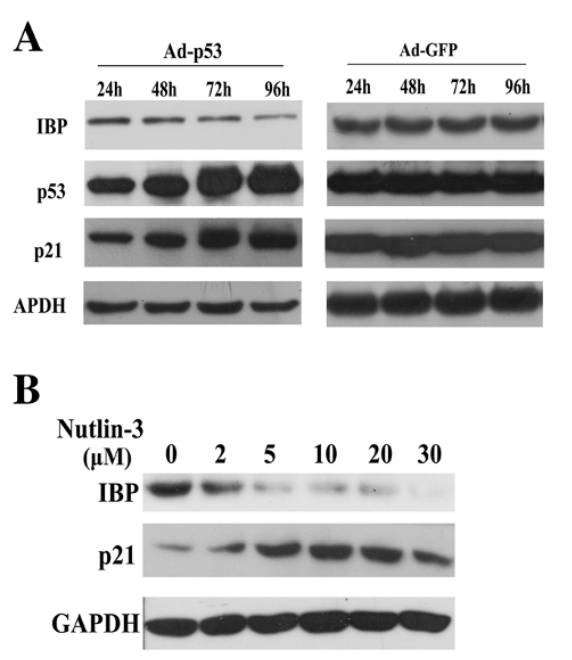

C

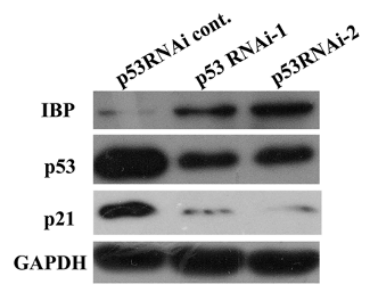

D

pifithrin- $\alpha$

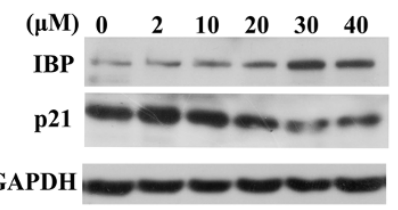

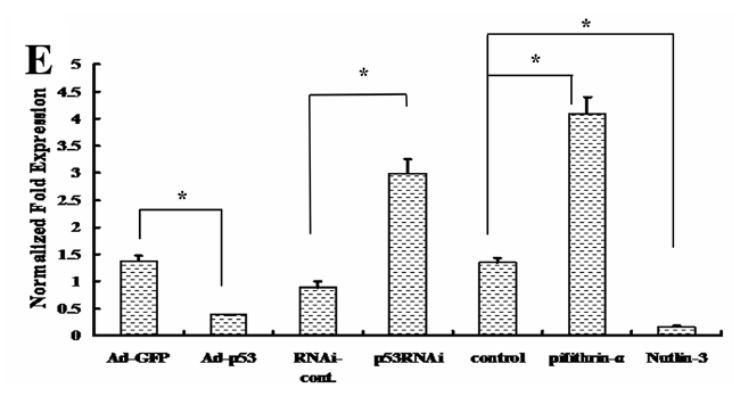

Figure 2 p53 attenuates IBP expression. (A and C) The expression of IBP and p53 in MCF-7 cells were tested by Western blot after Ad-p53 infection at different time points (A) or p53 RNAi lentiviruses infection (C). Ad-GFP or p53 RNAi cont. was a respective control. (B and D) The expression of IBP was detected by Western blot in MCF-7 cells treated with different concentrations of Nutlin-3 (B) or pifithrin-a (D). GAPDH and p21 served as controls. (E) Real-time PCR analysis of the expression of IBP in MCF-7 cells treated with Ad-p53 (96 h), p53-RNAi, Nutlin-3(10 $\mu$ mol/L for $8 \mathrm{~h}$ ) or pifithrin-a (30 $\mu \mathrm{mol} / \mathrm{L}$ for $24 \mathrm{~h}) ; \mathrm{GAPDH}$ was used as a control. *,$p<0.01$.

in vivo. Taken together, these results show that IBP is a direct transcriptional target of p53.

\section{IBP is suppressed by DNA damaging agents}

Because p53 may be an important mediator of chemotherapeutic toxicity in breast cancer and is induced by DNA damage as a sensor for damaged DNA, we tested whether IBP expression was changed by DNA damaging agents. Cisplatin suppressed IBP expression in a dose-dependent manner in MCF-7 and ZR-75-1 cells that express wild type p53 (Figure 4A). We also detected IBP expression in MCF-7 cells $96 \mathrm{~h}$ after cisplatin treatment. IBP expression was suppressed by cisplatin in a time-dependent manner within 96h (see Additional file 2). Furthermore, IBP was suppressed with the DNA damaging agent doxorubicin both in MCF-7 and ZR-751 cells (Figure 4B). To investigate the p53 dependence of DNA damaging agent-mediated IBP inhibition, we used p53 deleted HCT116 p53 ${ }^{-/-}$cells. IBP was suppressed with cisplatin in HCT116 $\mathrm{p}^{+/+}$cells, but was unaffected in HCT116 p53 $3^{-/-}$cells (Figure 4C). Similar results were obtained in MCF-7 cells stably expressing p53 RNAi (Figure 4D). These data indicate that the suppression of IBP by genotoxic stress in breast cancer cells is $\mathrm{p} 53$ dependent.

\section{IBP regulates the sensitivity to cisplatin-induced apoptosis in MCF-7 cells}

It has been shown that p53 pathway is inactive in cisplatin-resistant MCF-7 breast cancer cells [8]. Since IBP is correlated with the malignant behaviour of human breast cancer cells [16] and is down-regulated by p53 and DNA damaging agent in MCF-7 cells, we explored the importance of IBP in the response of MCF-7 to cisplatin. We first established stable IBP over-expressing (IBP/MCF-7) and stable IBP knockdown MCF-7 cells (MCF-7/IBPRNAi) (Figure 5A). Subsequently, IBP/MCF-7, MCF-7/ IBP-RNAi and the corresponding control cells were exposed to cisplatin, and cell growth were measured. Over-expression of IBP increased proliferation and survival of MCF-7 cells, and IBP knockdown increased cisplatin sensitivity of MCF-7 cells (Figure 5B). The IC50 values on IBP knockdown, IBP over-expression, RNAicontrol and pEGFP-C1 cells of cisplatin for $24 \mathrm{~h}$ were 6.96 


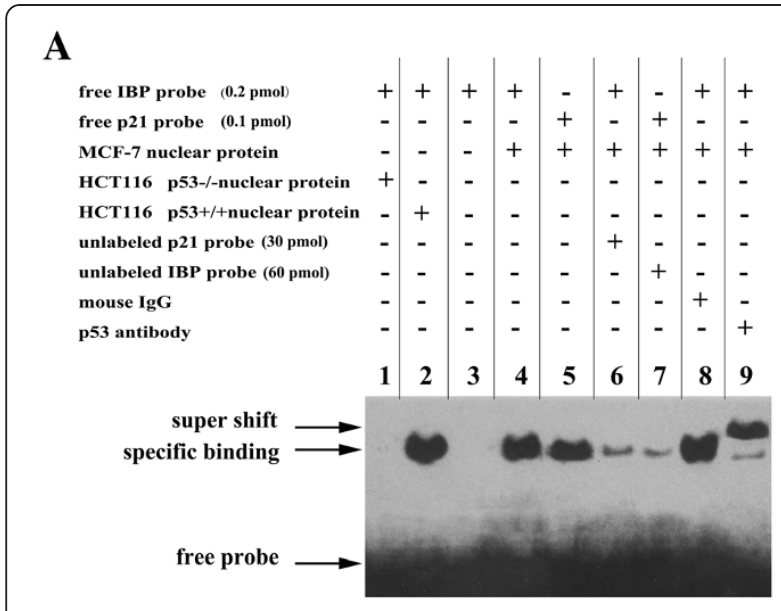

B

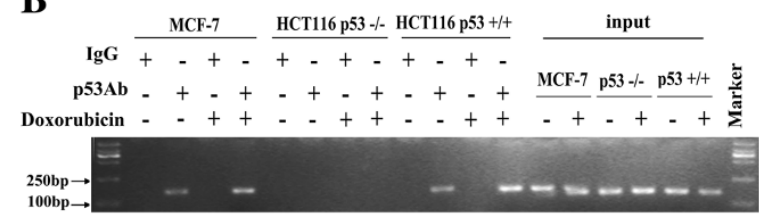

Figure 3 Recruitment of the $\mathbf{p} 53$ protein to the IBP promoter.

(A) EMSA assay demonstrating the ability of p53 to bind the IBP promoter in vitro. The binding reactions were performed with nuclear extracts and various labelled oligonucleotides in the presence of unlabelled probes or antibodies as indicated. HCT116 p53 $3^{-/-}$nuclear proteins were extracted as a negative control. A p21 probe served as a positive control. The band was supershifted using an antibody against p53. Mouse $\lg G$ served as a supershift negative control. (B) ChIP assay was performed using an anti-p53 antibody to test whether the $\mathrm{p} 53$ protein could bind the IBP promoter in HCT1 $16 \mathrm{p} 53^{+/+}, \mathrm{HCT} 116 \mathrm{p} 53^{-/-}$and MCF-7 cells. Cells were treated with $50 \mathrm{nmol} / \mathrm{L}$ doxorubicin for $8 \mathrm{~h}$. Mouse $\lg \mathrm{G}$ was used as a negative control.

$\pm 0.63 \mu \mathrm{g} / \mathrm{ml}, 23.10 \pm 5.36 \mu \mathrm{g} / \mathrm{ml}, 12.7 \pm 2.4 \mu \mathrm{g} / \mathrm{ml}$ and $12.57 \pm 1.90 \mu \mathrm{g} / \mathrm{ml}$, respectively (Figure $5 \mathrm{C}$ ).

Therefore the decreased survival with cisplatin in MCF7/IBP-RNAi cells was in large part due to an increase cell death. To confirm that IBP depletion increased cisplatin induced apoptosis in MCF-7 cells, we tested PARP and Annexin V-PI expression. When the cells were treated with cisplatin for $24 \mathrm{~h}$, more cleaved PARP was detected in the MCF-7/IBP-RNAi cells (Figure 6A). In addition, MCF-7/ IBP-RNAi cells showed increased percentage of Annexin $\mathrm{V}$-PI positive cells $12 \mathrm{~h}$ after cisplatin treatment (Figure 6B). These results demonstrate that IBP participates in the suppression of cisplatin-induced apoptosis in MCF-7 cells.

IBP over-expression inactivates p53 pathway through AKT Since IBP suppressed cisplatin induced apoptosis, we further investigated the effect of IBP on cisplatin-induced apoptotic signals. Stabilization and activation of wild type p53 are critical for cisplatin-mediated apoptosis. We tested whether the mechanism of IBP-induced cisplatin resistance was associated with p53 inactivation. Expression of p53 target gene p21 was used to monitor p53 pathway activity. As shown in Figure 7A, the basal expression of p53 in the IBP knockdown MCF-7 cells was markedly elevated. The p21 expression was consistent with p53 expression in IBP-knockdown and IBP-over-expressing MCF-7 cells. Furthermore, we detected cisplatin-induced p53 phosphorylation at Ser-15. In IBP-knockdown cells, increased level of phosphorylated p53 could be induced by cisplatin, whereas lower level p53 Ser-15 phosphorylation was detected in the IBP-over-expressing MCF-7 cells (Figure 7B). This data suggests that IBP over-expression in breast cancer cells decreases p53 accumulation and activation in response to cisplatin.

Members of the Bcl-2 family also are key players in regulating apoptosis. The apoptotic process is regulated by the ratio between Bax and its antiapoptotic counterpart $\mathrm{Bcl}-2$. It is also known that p53 negatively regulates $\mathrm{Bcl}-2$ expression and that wild-type p53 neutralises the deathprotective function of $\mathrm{Bcl}-2[25,26]$. We tested $\mathrm{Bcl}-2$ and Bax levels in IBP-over-expressing MCF-7 cells. The levels of Bcl-2 were highly elevated in IBP-over-expressing MCF-7 cells, and Bax expression was markedly reduced (Figure 7A). This result shows that IBP regulates $\mathrm{Bcl}-2$ family expression, and IBP disruptes p53 dependent apoptotic pathway in breast cancer cells. Thus, there is a positive feedback loop between IBP and p53 pathway.

All p53 auto-regulatory loops are either induced by p53 at the transcriptional level or regulated by p53-induced proteins [27]. It is known that AKT, which is closely associated with DNA damage, induces the phosphorylation of MDM-2 protein, which results in the translocation of MDM-2 into the nucleus where it inactivates p53 [28]. Because the closest homolog of IBP, SWAP-70 [9], is required for the proper activation of AKT [29], we tested whether IBP may also activate AKT. We found high level of AKT Ser-473 and MDM2 Ser-166 phosphorylation in IBP-over-expressing MCF-7 cells (Figure 7C). Moreover, when we treated IBP-over-expressing MCF-7 cells with AKT inhibitor Ly294002 or wortmannin, p53 and p21 expression was elevated, and MDM2 phosphorylation was decreased (Figure 7D). Further, p21 expression in IBPover-expressing MCF-7 cells treated with Ly294002 or wortmannin for $24 \mathrm{~h}$ was quantified (see Additional file 3). These results suggest that IBP may negatively regulate p53 activation through AKT in MCF-7 cells.

\section{IBP regulates the sensitivity to cisplatin partly through AKT/p53 pathway}

Since IBP over-expression in turn negatively regulates p53 expression, We further investigated whether IBP regulates the sensitivity to cisplatin in p53-dependent manner. In stable MCF-7/IBP-RNAi cells, we inhibited p53 expression by p53 targeting RNAi lentiviral infection, then cells 


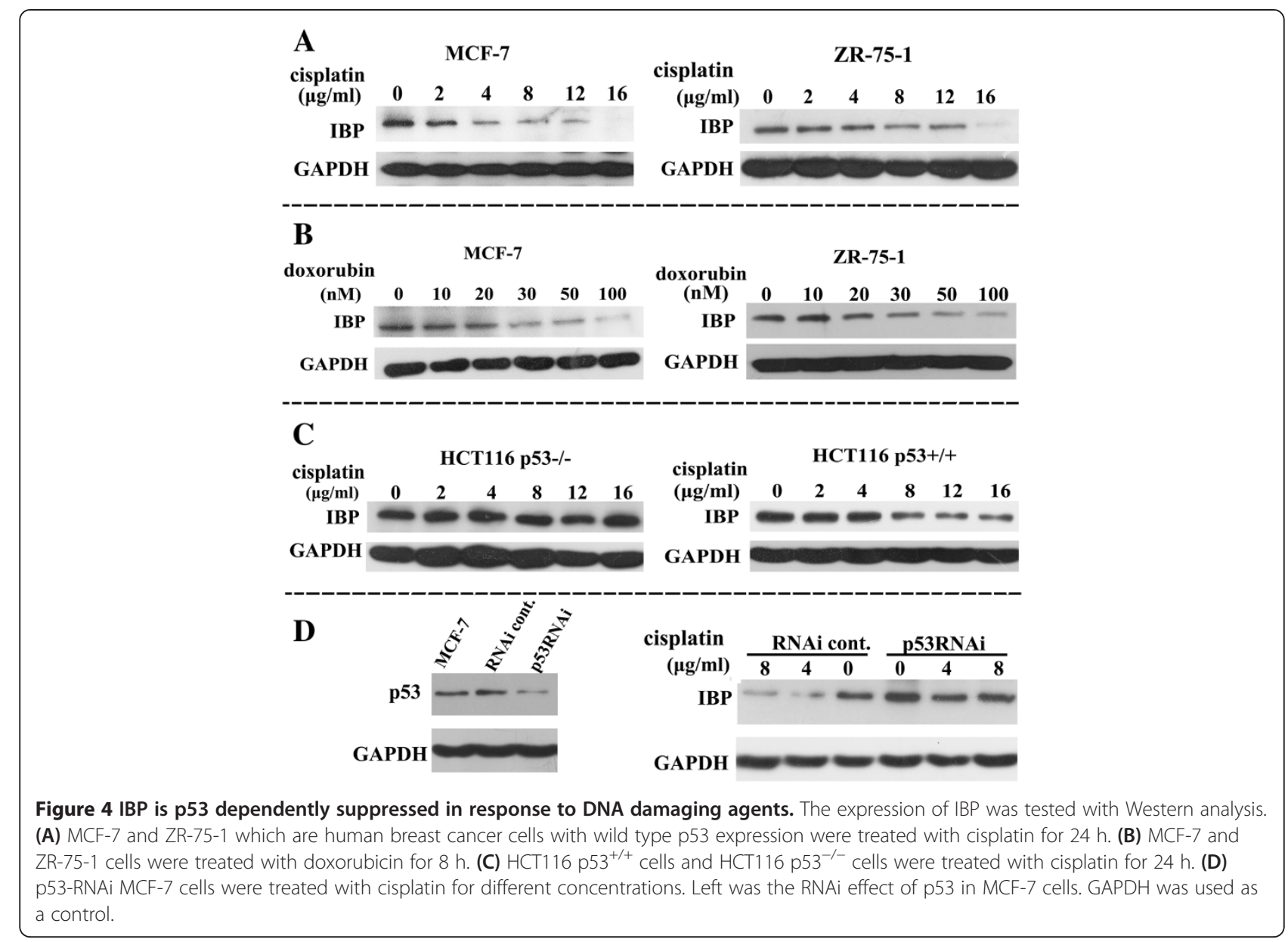

were exposed to cisplatin, and cell growth was measured. Inhibition of p53 could decrease cisplatin sensitivity in IBP-knockdown MCF-7 cells (Figure 8A). Moreover, we established stable IBP-knockdown HCT116 $\mathrm{p} 53^{-/-}$cells, and measured cisplatin-induced cell growth suppression in these cells by using CCK-8. As shown in Figure 8B, IBP knockdown also increased cisplatin sensitivity of HCT116 p53 ${ }^{-/-}$cells. Furthermore, in IBP-over-expressing MCF-7 cells, AKT inhibitors Ly294002 could attenuate cisplatin resistance and increase cisplatin induced apoptosis (Figure $8 \mathrm{C}$-D). These results suggest that IBP may impair cisplatin chemosensitivity in breast cancer cells partly through AKT/p53 pathway.

\section{Discussion}

IBP is a newly discovered protein aberrantly expressed in breast cancer cells. We found that IBP promotes the proliferation and migration of breast cancer cells and its expression is negatively correlated with p53 levels [16]. Previous studies have shown the role of Lck in IBP activation in $\mathrm{T}$ lymphoma cells [12]. However, little is known about the regulation of IBP expression, particularly in breast cancer. Because previous studies have shown that the activity of Rac1 (a downstream molecule of IBP) is inversely regulated by functional p53 [30,31], we investigated whether p53 could regulate IBP in breast cancer cells. Here we have identified IBP as a novel p53 target gene. The inhibition of IBP expression corresponded with increased p53 expression, and the induction of IBP was related to p53. p53 could bind to IBP promoter in MCF-7 cells. The present results clearly indicate that inactivation of wild-type p53 at least partially explains the aberrant IBP expression in breast cancer.

It was previously reported that p53 could transactivate genes from a noncanonical consensus $1 / 2$-site or $3 / 4$ sites that contain a $1 / 4$-site that is adjacent to a $1 / 2$-site or a $1 / 4$-site and is separated from a $1 / 2$-site by a 5 -nt spacer [32]. We have shown for the first time that IBP promoter region possesses a noncanonical repressing p53-binding site. We identified that IBP promoter contains a "perfect" p53 half site, which contains a CATG core motif. It is known that the $\mathrm{C}$ and $\mathrm{G}$ positions are essential for the function of the p53-binding site, and the presence of an "AT" as the "WW" dinucleotide is associated with the high activity of a half site [2,33]. Ren's group reported that CATG core was an activating 


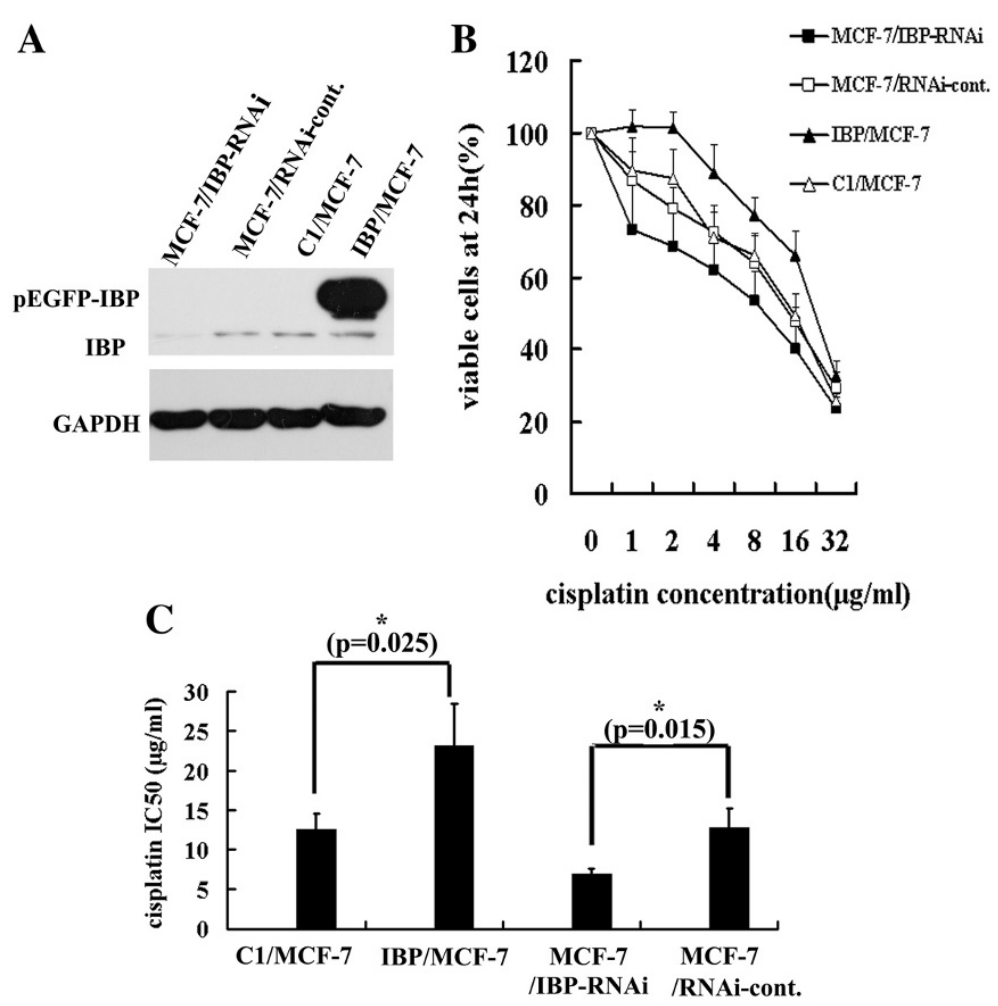

Figure 5 IBP regulates sensitivity to cisplatin in MCF-7 cells. (A) IBP expression was analyzed by Western blot in stable IBP-over-expressing MCF-7 cells and IBP-knockdown MCF-7 cells. C1/MCF-7 and MCF-7/RNAi-cont. cells were respective control cells. (B) Cells were treated with increasing cisplatin concentrations, and their proliferation rates were measured with a CCK-8 assay. (C) Cisplatin IC50 values were determined by CCK cell survival assays. In the columns, the mean was derived from at least three independent experiments. A statistical analysis was performed using Student's $t$ test. ${ }^{*}, \mathrm{p}<0.05$, significant.

core, but the nucleotides adjacent to the CWWG motif could modulate p53 function to become repressive, and repressing p53 response elements had a much higher frequency of noncanonical nucleotides in the position immediately adjacent to the CWWG motif [34]. The triplet flanking sequences in the p53-binding site of IBP promoter also differ from the canonical p53-binding site motif. However, whether the triplet flanking sequences in the half p53-binding site or the $1 / 4$-site that is adjacent to a $1 / 2$-site modulate the p53 response element behaviour in IBP promoter, needs further investigation. In addition, it has been shown that p53 mutants can also transactivate gene expression at noncanonical sites [32,33]. Noncanonical sequences may exhibit responsiveness to p53 in combination with other transcription factors, such as the estrogen receptor [33]. In this study, although the role of the p53 mutants or the possible cofactors in IBP transcription in breast cancer remains to be determined, further experiments will elucidate the mechanism of aberrant IBP expression in breast cancer cells.

So far little information is available concerning the function of IBP, especially in breast cancer. IBP is a GEF related to the Rho GTPases. Recent study showed a new function for GEFs in the modulation of cell death after genotoxic stress [35]. It is also reported that Cdc42 activity downstream of IBP might regulate mammalian genomic stability [36]. In the present study, we have shown that IBP is decreased upon exposure to DNA damaging agents in a p53 dependent manner. It is known that the status of p53 is associated with resistance to DNA-damaging therapies $[37,38]$. p53 mutations are common in breast cancer cells and p53 inactivation is an important cause for cisplatin resistance [8]. p53 pathway plays an important role in DNA damage mediated apoptotic signals. Here we further demonstrated that IBP regulated cisplatin-mediated apoptosis in MCF-7 cells. IBP over-expression increased cisplatin resistance in MCF-7 cells. The response to DNA damaging agent and the mechanisms of cisplatin resistance are complex and multifactorial. It is likely that IBP is one of the mediators for a p53-dependent cisplatin response in breast cancer cells. Mechanisms that inhibit the propagation of DNA damage signalling to the apoptotic machinery are complex. We found that IBP over-expression in MCF7 cells suppressed the basal protein expression of p53 and p21, attenuated p53 phosphorylation, changed the ratio between Bax and Bcl-2, and activated AKT. It is known that in chemoresistant cells cisplatin induced p53 phosphorylation is attenuated, particularly on Ser15 and Ser20, and 


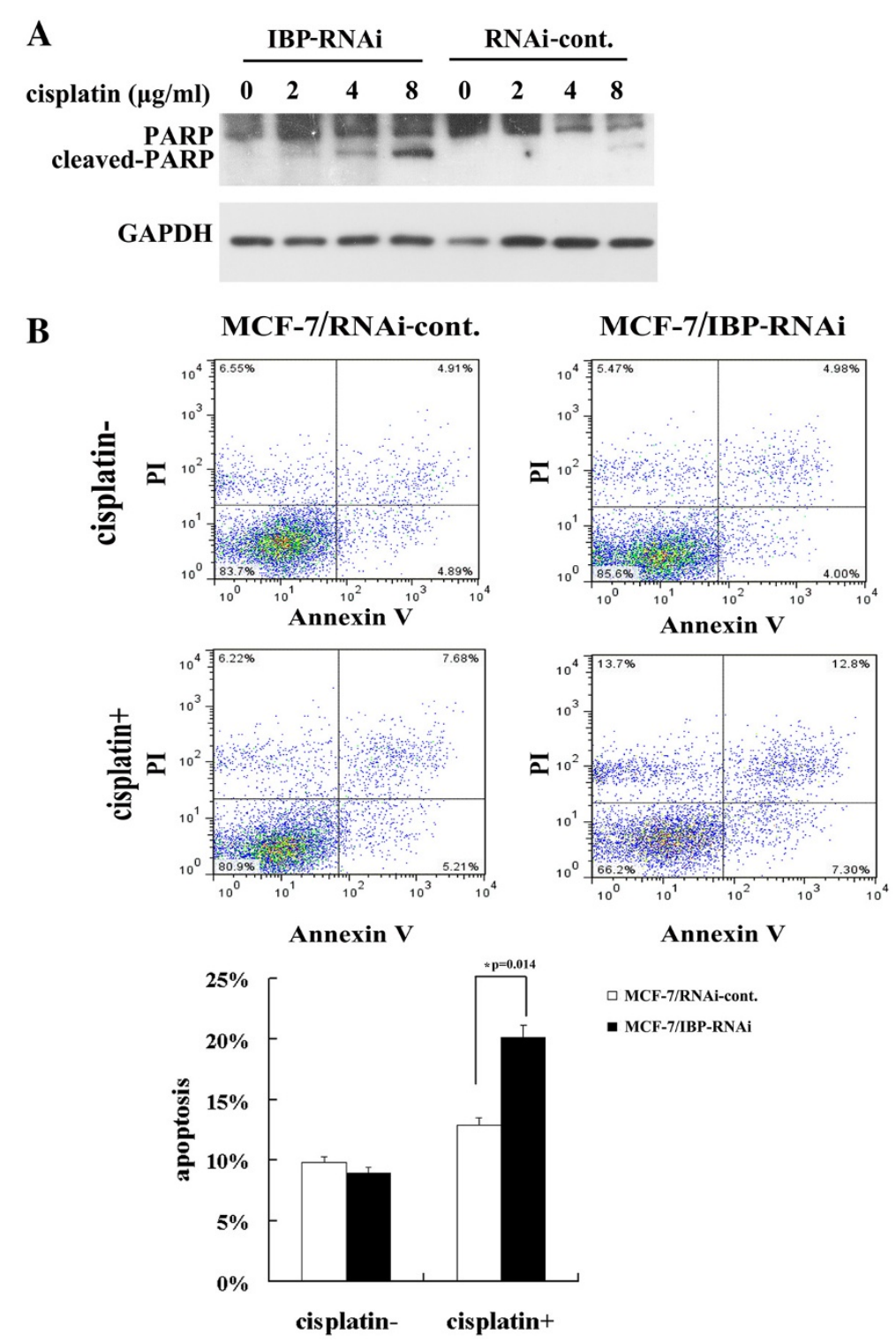

Figure 6 IBP knockdown results in increased cisplatin-mediated apoptotic cell death. (A) After a $24 \mathrm{~h}$ cisplatin treatment, the cell lysates of the MCF-7/IBP-RNAi cells and the control cells were prepared, and the cytoplasmic marker of apoptosis (cleaved PARP) was detected by western blot. (B) MCF-7/IBP-RNAi cells and the control cells were treated with $2 \mu \mathrm{g} / \mathrm{ml}$ cisplatin to induce apoptosis. The apoptosis was detected at $12 \mathrm{~h}$ after cisplatin treatment by Alexa fluor 647 conjugated Annexin V-PI assays.

the phosphorylation of Ser15 and Ser20 plays an important role in the transduction of p53-mediated apoptosis [39]. These results indicate that IBP plays a role in increased cisplatin resistance in at least three aspects: the loss of p53 function, over-expression of antiapoptotic Bcl-2, and activation of the PI3K/AKT pathway. Although our data explained in partly the mechanisms of IBP-mediated suppression of breast cancer cell apoptosis in response to cisplatin, whether this function is related to RhoGTPase (e.g. Cdc42) is still unknown. Other study has shown that p53mediated reactive oxygen species (ROS) production could also be a mechanism of cisplatin-induced apoptosis [40]. It is clear that Rac1 is an important regulator of ROS production [41,42]. Whether IBP regulates cisplatin resistance through Rac1 and ROS remains to be confirmed. In addition, it is interesting that our results also suggest that IBP over-expression in breast cancer cells may possibly induce a potential p53 regulatory feedback loop.

\section{Conclusions}

In summary, we provide evidence that IBP, which is a direct target gene of $\mathrm{p} 53$, is inversely regulated by $\mathrm{p} 53$. We observed that IBP over-expression decreases cisplatinmediated breast cancer cell apoptosis, while IBP suppression 


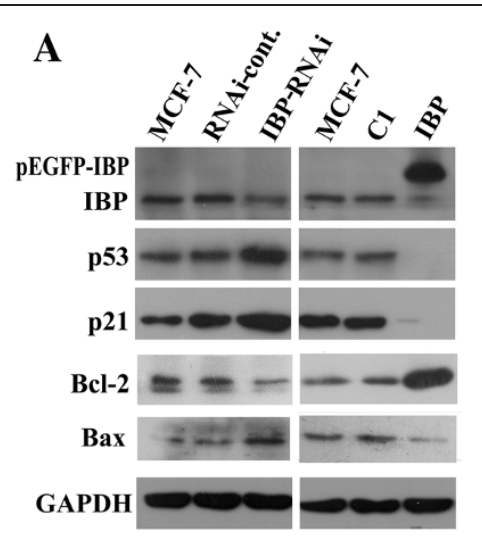

\section{B}

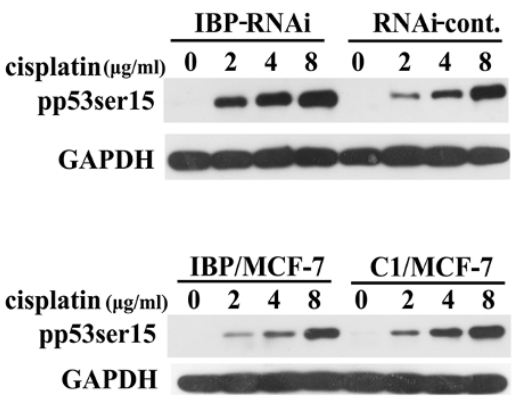

C

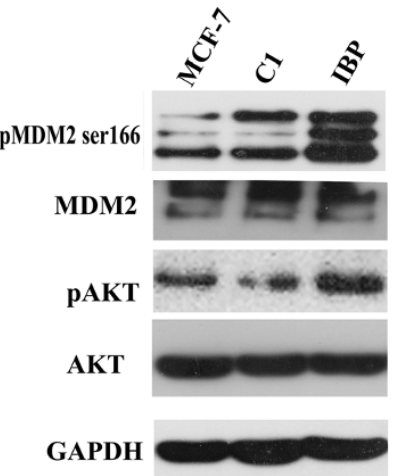

D

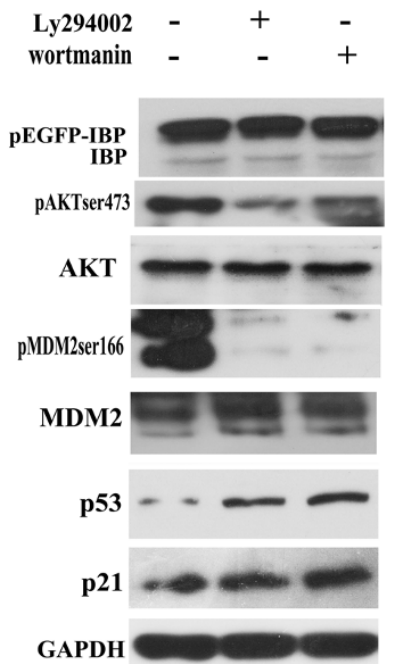

Figure 7 IBP over-expression activates p53 pathway though AKT. (A) The relative basal expression levels of IBP, p53, p21, BCl-2, and Bax in the IBP-knockdown MCF-7 cells (IBP-RNAi) and IBP-over-expressing MCF-7 cells (IBP). (B) The expression of p53 Ser-15 phosphorylation was tested in IBP-over-expressing MCF-7 cells and IBP knockdown cells treated with cisplatin for $24 \mathrm{~h}$. (C) Western analysis of levels AKT Ser-473, MDM2 Ser166 phosphorylation in IBP-over-expressing MCF-7 cells and control cells. (D) The expression of MDM2 Ser-166 phosphorylation, p53 and p21 were detected in IBP-over-expressing MCF-7 cells treated with Ly294002 or wortmannin for 24 h. GAPDH served as a loading control.

reduces cisplatin resistance. We also observed that IBP is a feedback regulator of $\mathrm{p} 53$. These observations promote our understanding of the relationship between IBP signalling and the p53 tumour suppressor. Therefore IBP may serve as a target for pharmacologic intervention of breast cancer resistant to cisplatin therapy.

\section{Materials and methods}

\section{Cell lines}

HEK293 cells and human breast cancer MCF-7 cells, ZR-75-1 cells, were purchased from the Type Culture Collection of the Chinese Academy of Sciences (Shanghai, China). The HCT116 p53 $3^{-/-}$and HCT116 p53 ${ }^{+/+}$ cell lines were gifts from Dr. Vogelstein (Johns Hopkins University, USA) [43] and Dr. Zhihua Liu (Chinese Academy of Medical Sciences and Peking Union Medical College, China) [44]. MCF-7 cells were grown in MEM medium that was supplemented with $10 \%$ foetal bovine serum, $1 \%$ non-essential amino acids and $10 \mu \mathrm{g} / \mathrm{ml}$ insulin. ZR-75-1 cells were grown in RPMI-1640 medium with $10 \%$ foetal bovine serum. HEK293 cells, HCT116 $\mathrm{p} 53^{-/-}$and $\mathrm{p} 53^{+/+}$cells were maintained in DMEM that was supplemented with $10 \%$ foetal bovine serum. All of the cells were maintained in a humidified atmosphere that contained $5 \% \mathrm{CO}_{2}$ at $37^{\circ} \mathrm{C}$.

\section{Plasmid construction and mutagenesis}

The $-1807 /+60,-979 /+60,-640 /+60,-294 /+60$ and $-116 /+60$ fragments of the human IBP gene (relative to the transcriptional start site) were amplified from the genomic DNA of MCF-7 cells by PCR using KOD polymerase (Toyobo). These amplified fragments were inserted into the KpnI and HindIII restriction sites of the pGL3-basic vector (Promega). The wild-type p53 expression plasmid, pCMV-p53, and the p53 mutant plasmid, pCMV-p53R175H, were kindly provided by 


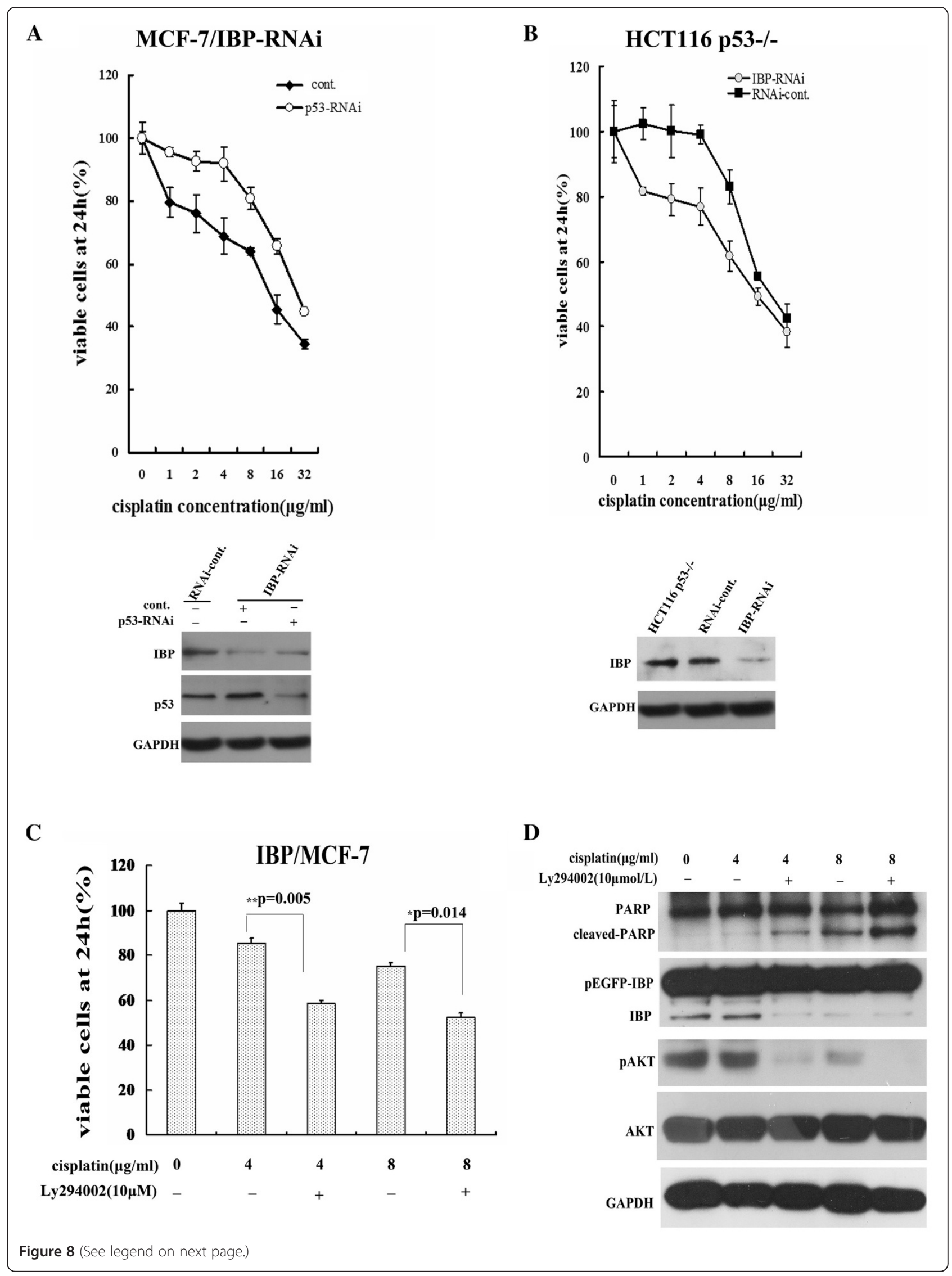


(See figure on previous page.)

Figure 8 IBP regulates the sensitivity to cisplatin partly through AKT/p53 pathway. (A) In stable MCF-7/IBP-RNAi cells, cells were infected with p53 targeting RNAi lentiviral or control lentiviral, and then treated with increasing cisplatin for $24 \mathrm{~h}$. Cell proliferation rates were measured with CCK-8 assay. (B) Stable IBP-knockdown HCT116 p53 $3^{-/-}$cells were treated with cisplatin for $24 \mathrm{~h}$ and cell proliferation were measured. (C and D) IBP over-expressing MCF-7 cells were treated with cisplatin and $10 \mu \mathrm{mol} / \mathrm{L}$ Ly294002 for $24 \mathrm{~h}$. Cell proliferation was measured by CCK-8 assay (C). Cleaved PARP and AKT Ser-473 phosphorylation were detected by western blot (D).

Dr. Vogelstein (Johns Hopkins University, USA). TaKaRa MutanBEST kit (TaKaRa) was used to introduce the p53 binding site into the IBP promoter deletion mutant. The following mutagenic primers were used: forward 5 ' $-\mathrm{CG}$ GGAGCCACGTGGATACAG-3', reverse 5' -TTTTAGA AGCCTCCTCAGACCC-3'. The pEGFP-C1-IBP expression plasmid was a gift from Dr. Alessandra B. Pernis (Columbia University, USA). All of the constructs were confirmed by DNA sequencing.

\section{Adenovirus infection and cell treatment}

Adenovirus(Ad)-p53 was purchased from Shenzhen SiBiono GeneTech Co. [44]. Ad-GFP was purchased from Shanghai Sunbio Medical Biotechnology Co. The cells were treated with different concentrations of doxorubicin (Sigma-Aldrich) for $8 \mathrm{~h}$, Nutlin-3 (Beyotime) for $24 \mathrm{~h}$ and pifithrin- $\alpha$ (Beyotime) for $24 \mathrm{~h}$. The cisplatin (Sigma-Aldrich) concentrations and experimental details are described in the text and figure legends. The cells were treated with Ly294002 (Beyotime) or wortmannin (Beyotime) for 24 h.

\section{RNA interference}

To knockdown IBP expression, double-stranded DNA oligonucleotides (forward, 5'-TGCTGTTCATCTGGA CATTCCAGTGTGTTTTGGCCACTGACTGACACAC 'TGGAGTCCAGATGAA-3' and reverse, 5'-CCTGTT CATCTGGACTCCAGTGTGTCAGTCAGTGGCCAAA ACACACTGGAATGTCCAGATGAAC-3') were subcloned into pcDNA ${ }^{\mathrm{Tm}} 6.2-\mathrm{GW} /$ EmGFPmiR (Invitrogen) using the BLOCK-iT Pol II miR RNAi Expression Vector Kit (Invitrogen). The RNAi plasmid or control plasmid, which contained a non-specific sequence, was transfected into MCF-7 cells. Lipofectamine 2000 (Invitrogen) was used as the transfection reagent. The growth medium was supplemented with blasticidin $(10 \mu \mathrm{g} / \mathrm{ml}$, Invitrogen $)$, which was used to select for blasticidin-resistant transfectants. For the p53 knockdown, double-stranded DNA oligonucleotides (forward, 5' -CCGGGACTCCAGTGGTAATC TACTTCAAGAGAGTAGATTACCACTGGAGTCTTT TTG-3' and reverse, 5' -AATTCAAAAAGACTCCAGT GGTAATCTACTCTCTTGAAGTAGATTACCACTGGA GTC-3') were subcloned into pMagic 1.1 and packaged into lentivirus particles (Shanghai Sunbio Medical Biotechnology Co.). One day after infection, the cell- growth medium was supplemented with puromycin ( $2 \mu \mathrm{g} / \mathrm{ml}$, Invitrogen) to select stable transfectants.

\section{Luciferase reporter assays}

Luciferase reporter assays were performed using the Dual-Luciferase $^{\circledR}$ Reporter Assay System (Promega). Cells were seeded in 24 -well plates $\left(1.0 \times 10^{5}\right.$ cells/well $)$ and transfected together with a promoter-reporter gene vector and the pRL-TK Renilla luciferase vector. After $48 \mathrm{~h}$ of transfection, the cells were harvested and analysed according to the manufacturer's instructions. The luciferase activities were normalised to the Renilla luciferase activity of the internal control.

\section{Western blotting}

Cell lysates were prepared in RIPA buffer (Beyotime). Whole-cell lysates were separated on a 10\% SDS-PAGE gel and transferred onto polyvinylidene difluoride (PVDF) membranes (Millipore). The membranes were blocked for $1 \mathrm{~h}$ at $37^{\circ} \mathrm{C}$ in $5 \%$ non-fat milk/TBST and were then incubated with primary antibodies overnight at $4^{\circ} \mathrm{C}$. Antibodies against IBP (produced as described previously) [16], p53 (sc-126, Santa Cruz), p21 (3733-1, Epitomics), PARP (9532, Cell Signaling), phospho-p53(Ser15) (9284, Cell Signaling), Bcl-2 (1017-1, Epitomics), Bax (AB026, Beyotime), phospho-AKT(Ser473) (4060, Cell Signaling), AKT(4691, Cell Signaling),phospho-MDM2(Ser166) (3521, Cell Signaling), MDM2(sc-965, Santa Cruz) and GAPDH (AG019, Beyotime) were used. The membrane was then rinsed in TBST and incubated with various secondary antibodies for $2 \mathrm{~h}$ at $25^{\circ} \mathrm{C}$. Immunoreactive bands were visualised with a chemiluminescent HRP substrate (Millipore).

\section{Quantitative RT-PCR}

Total RNA was isolated using TRIzol (Invitrogen), and $1 \mu \mathrm{g}$ of isolated RNA was reverse transcribed to generate cDNAs (TaKaRa). Amplification was performed by using SYBR Premix Ex Taq II (TaKaRa). The primers used for amplification included the following: IBP forward, 5'-GA GGGCTGACGAGGATGTGG-3' and reverse, 5'-GCTG GTGACCGGACGCTTAT-3'; and GAPDH forward, 5'-A ATCCATCACCATCTTCCA-3' and reverse, 5' -TGGAC TCCACGACGTACTCA-3'. GAPDH mRNA levels were determined as an internal control. 


\section{Electrophoretic mobility shift assays (EMSA)}

Nuclear extracts were prepared in hypertonic buffer (420 mM NaCl, $1.5 \mathrm{mM} \mathrm{MgCl} 2,0.5 \mathrm{mM}$ DTT, $0.2 \mathrm{mM}$ EDTA, $0.5 \mathrm{mM}$ PMSF, 25\% glycerol, $5 \mu \mathrm{g} / \mathrm{ml}$ aprotinin, $5 \mu \mathrm{g} / \mathrm{ml}$ phenanthroline, $3 \mu \mathrm{g} / \mathrm{ml}$ pepstatin A and $20 \mathrm{mM}$ HEPES). Double-stranded oligonucleotide probes that were derived from the IBP gene promoter (sense strand, 5' -TAAAAGGGCCTCACATGCCCCGGGAGCCAC-3' ) and $p 21$ gene promoter (sense strand, 5'-GGAAGAA GACTGGGCATGTCTGGGCAGAGA-3') [44] were labelled with $\gamma^{-}{ }^{32} \mathrm{P}$-ATP using T4 polynucleotide kinase. The nuclear extracts $(8 \mu \mathrm{g})$ were incubated with the probe for $30 \mathrm{~min}$ at $30^{\circ} \mathrm{C}$. The protein-DNA complexes were resolved using non-denaturing PAGE and were detected by autoradiography. For the cold probe competition assay, unlabelled probe was added to the nuclear protein extracts one hour before the detection was performed. In the supershift assay, $1 \mu \mathrm{l}$ of an anti-p53 antibody (sc-126x, Santa Cruz) was incubated with the nuclear extracts for $1 \mathrm{~h}$ at room temperature prior to the addition of the radiolabeled probe and the implementation of PAGE.

\section{Chromatin immunoprecipitation assay (ChIP)}

The ChIP assays were performed using an EZ-ChIP ${ }^{\mathrm{TM}}$ Chromatin Immunoprecipitation Kit (Upstate) following the manufacturer's instructions. Briefly, cells were crosslinked with $1 \%$ formaldehyde and a p53 antibody (sc-126, Santa Cruz) or control IgG, which was used to precipitate the crosslinked protein/chromatin. The DNA fragments were analysed using PCR with a primer set (forward, $5^{\prime}-\mathrm{T}$ TTTCCCTCAGCAAGCTGCGTCTGG-3' and reverse, 5' -CTGCATGGGAACTGGGGACCAACTCT-3') that was designed to amplify the -305 to -150 region of the IBP gene that harbours p53-binding site.

\section{Cell survival assays}

A cell survival assay was performed in triplicate with a Cell Counting Kit-8 (CCK-8, Beyotime). The cells were seeded in 96-well plates at $5 \times 10^{3}$ cells/well $(100 \mu \mathrm{l} /$ well) $24 \mathrm{~h}$ before the cisplatin treatment. The culture medium was then replaced with fresh medium that contained different concentrations of cisplatin, which ranged from 0 to $32 \mu \mathrm{g} / \mathrm{ml}$, and the cells were cultured in this medium for $24 \mathrm{~h}$. Following the incubation, $10 \mu \mathrm{l}$ of CCK- 8 solution was added to each well, and after $1 \mathrm{~h}$, the absorbance value of each well was read at $450 \mathrm{~nm}$. The cell growth rate was calculated as the ratio of the absorbance of the experimental well to that of the blank well. The IC50 values (the drug concentration that results in a $50 \%$ absorbance reduction compared to the control) were calculated.

\section{Annexin V-PI flow cytometry assay}

Flow cytometry assay was performed by using Caliber II sorter and Cell Quest FACS system (BD Biosciences). Alexa fluor 647 conjugated Annexin V (invitrogen) and PI (Invitrogen) was incubated for $15 \mathrm{~min}$ according to the manufacturer's protocol. About $10^{4}$ cells were measured per sample.

\section{Additional files}

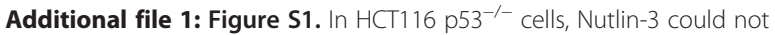
decrease IBP expression. IBP expression was detected by western blot when $\mathrm{HCT} 116 \mathrm{p} 53^{-/-}$cells were treated with different concentration of Nutlin-3 for $8 \mathrm{~h}$.

Additional file 2: Figure S2. IBP expression is not increase in response to cisplatin within $96 \mathrm{~h}$ in MCF-7 cells. IBP and p53 expression was detected by western blot when MCF-7 cells were treated with $8 \mu \mathrm{g} / \mathrm{ml}$ cisplatin continuously for $12 \mathrm{~h}$ to $96 \mathrm{~h}$.

Additional file 3: Figure S3. Quantification analysis for p21 expression in IBP-over-expressing MCF-7 cells treated with Ly294002 or wortmannin for $24 \mathrm{~h}$.
\end{abstract}

\section{Abbreviations}

Ad: Adenovirus; ChIP: Chromatin immunoprecipitation; EMSA: Electrophoretic mobility-shift assay; GEF: Guanine nucleotide exchange factor; GFP: Green fluorescent protein; IBP: Interferon regulatory factor 4 binding protein; PARP: Poly-ADP ribose polymerase; RNAi: RNA interference.

\section{Competing interests}

The authors declare that they have no competing of interests.

\section{Authors' contributions}

MY and $\mathrm{CH}$ designed the study. MY, FY and ZC performed the experiments and analysed and interpreted the results. PL and $A C$ provided technical and material support. MY wrote the manuscript. PL and SL revised the manuscript. CH supervised the study. All authors read and approved the final manuscript.

\section{Acknowledgments}

This work was supported by the National Natural Science Foundation of China (grant number 81172538, 30901458, 81072154) and the National Basic Research Program of China (973 Program) (grant number 2010CB529403).

\section{Author details}

${ }^{1}$ Department of Clinical Biochemistry, Third Military Medical University, Chongqing 400038, P.R. China. ${ }^{2}$ Department of Cell Biology, Third Military Medical University, Chongqing 400038, P.R. China. ${ }^{3}$ Urology Institute of People's Liberation Army, Southwest Hospital, Third Military Medical University, Chongqing 400038, P.R. China.

Received: 5 April 2012 Accepted: 2 August 2012

Published: 13 August 2012

\section{References}

1. Levine AJ, Oren M: The first 30 years of $\mathrm{p} 53$ : growing ever more complex. Nat Rev Cancer 2009, 9:749-758.

2. Menendez D, Inga A, Resnick MA: Potentiating the p53 network. Discov Med 2010, 10:94-100.

3. Parkin DM, Bray F, Ferlay J, Pisani P: Global cancer statistics, 2002. Ca-a Cancer J Clin 2005, 55:74-108.

4. Lai H, Lin L, Nadji M, Lai S, Trapido E, Meng L: Mutations in the p53 tumor suppressor gene and early onset breast cancer. Cancer Biol Ther 2002, $1: 31-36$.

5. Olivier M, Hussain SP, Caron de Fromentel C, Hainaut P, Harris CC: TP53 mutation spectra and load: a tool for generating hypotheses on the etiology of cancer. IARC Sci Publ 2004, 157:247-270. 
6. Jerry DJ, Dunphy KA, Hagen MJ: Estrogens, regulation of $p 53$ and breast cancer risk: a balancing act. Cellular Mol Life Sci 2010, 67:1017-1023.

7. Manic S, Gatti L, Carenini N, Fumagalli G, Zunino F, Perego P: Mechanisms controlling sensitivity to platinum complexes: role of p53 and DNA mismatch repair. Curr Cancer Drug Targets 2003, 3:21-29.

8. Eckstein N, Servan K, Girard L, Cai D, von Jonquieres G, Jaehde U, Kassack MU, Gazdar AF, Minna JD, Royer HD: Epidermal growth factor receptor pathway analysis identifies amphiregulin as a key factor for cisplatin resistance of human breast cancer cells. J Biol Chem 2008, 283:739-750.

9. Gupta S, Lee A, Hu CM, Fanzo J, Goldberg I, Cattoretti G, Pernis AB: Molecular cloning of IBP, a SWAP-70 homologous GEF, which is highly expressed in the immune system. Hum Immunol 2003, 64:389-401.

10. Oka T, Ihara S, Fukui Y: Cooperation of DEF6 with activated Rac in regulating cell morphology. J Biol Chem 2007, 282:2011-2018.

11. Samson T, Will C, Knoblauch A, Sharek L, von der Mark K, Burridge K, Wixler $\checkmark$ : Def-6, a guanine nucleotide exchange factor for Rac1, interacts with the skeletal muscle integrin chain alpha 7A and influences myoblast differentiation. J Biol Chem 2007, 282:15730-15742.

12. Gupta S, Fanzo JC, Hu CM, Cox D, Jang SY, Lee AE, Greenberg S, Pernis AB: $T$ cell receptor engagement leads to the recruitment of IBP, a novel guanine nucleotide exchange factor, to the immunological synapse. $J$ Biol Chem 2003, 278:43541-43549.

13. Chen Q, Gupta S, Pernis AB: Regulation of TLR4-mediated signaling by IBP/Def6, a novel activator of Rho GTPases. J Leukoc Biol 2009, 85:539-543.

14. Fanzo JC, Yang W, Jang SY, Gupta S, Chen QZ, Siddiq A, Greenberg S, Pernis AB: Loss of IRF-4-binding protein leads to the spontaneous development of systemic autoimmunity. J Clin Invest 2006, 116:703-714.

15. Subramanian S, West RB, Marinelli RJ, Nielsen TO, Rubin BP, Goldblum JR, Patel RM, Zhu S, Montgomery K, Ng TL, et al: The gene expression profile of extraskeletal myxoid chondrosarcoma. J Pathol 2005, 206:433-444.

16. Li P, Zhang ZJ, Wang QL, Li SH, Zhang Y, Bian XW, Chen A, Hu CM: The ectopic expression of IFN regulatory factor 4-binding protein is correlated with the malignant behavior of human breast cancer cells. Int Immunopharmacol 2009, 9:1002-1009.

17. Zhang Z, Wang Q, Li P, Zhou Y, Li S, Yi W, Chen A, Kong P. Hu C: Overexpression of the Interferon regulatory factor 4-binding protein in human colorectal cancer and its clinical significance. Cancer Epidemiol 2009, 33:130-136.

18. Messeguer X, Escudero R, Farre D, Nunez O, Martinez J, Alba MM: PROMO: detection of known transcription regulatory elements using speciestailored searches. Bioinformatics 2002, 18:333-334.

19. Farre D, Roset R, Huerta M, Adsuara JE, Rosello L, Alba MM, Messeguer X: Identification of patterns in biological sequences at the ALGGEN server: PROMO and MALGEN. Nucleic Acids Research 2003, 31:3651-3653.

20. el-Deiry WS, Kern SE, Pietenpol JA, Kinzler KW, Vogelstein B: Definition of a consensus binding site for p53. Nat Genet 1992, 1:45-49.

21. Jordan JJ, Menendez D, Inga A, Nourredine M, Bell D, Resnick MA: Noncanonical DNA Motifs as Transactivation Targets by Wild Type and Mutant p53. Plos Genetics 2008, 4:e1000104.

22. Vassilev LT, Vu BT, Graves B, Carvajal D, Podlaski F, Filipovic Z, Kong N, Kammlott U, Lukacs C, Klein C, et al: In vivo activation of the p53 pathway by small-molecule antagonists of MDM2. Science 2004, 303:844-848.

23. Komarov PG, Komarova EA, Kondratov RV, Christov-Tselkov K, Coon JS, Chernov MV, Gudkov AV: A chemical inhibitor of $\mathrm{p} 53$ that protects mice from the side effects of cancer therapy. Science 1999, 285:1733-1737.

24. Shirley SH, Rundhaug JE, Tian J, Cullinan-Ammann N, Lambertz I, Conti CJ, Fuchs-Young R: Transcriptional Regulation of Estrogen Receptor-alpha by p53 in Human Breast Cancer Cells. Cancer Res 2009, 69:3405-3414.

25. Moll UM, Tomita Y, Marchenko N, Erster S, Nemajerova A, Dehner A, Klein C, Pan HG, Kessler H, Pancoska P: WT p53, but not tumor-derived mutants, bind to $\mathrm{BCl} 2$ via the DNA binding domain and induce mitochondrial permeabilization. J Biol Chem 2006, 281:8600-8606.

26. Wu Y, Mehew JW, Heckman CA, Arcinas M, Boxer LM: Negative regulation of bcl-2 expression by p53 in hematopoietic cells. Oncogene 2001, 20:240-251.

27. Harris SL, Levine AJ: The p53 pathway: positive and negative feedback loops. Oncogene 2005, 24:2899-2908.

28. Zhou BP, Liao Y, Xia W, Zou Y, Spohn B, Hung MC: HER-2/neu induces p53 ubiquitination via Akt-mediated MDM2 phosphorylation. Nat Cell Biol 2001, 3:973-982.
29. Sivalenka RR, Sinha M, Jessberger R: SWAP-70 regulates mast cell Fc epsilon RI-mediated signaling and anaphylaxis. Eur J Immunol 2008, 38:841-854

30. Zheng Y, Guo FK, Gao Y, Wang L: P19(Arf)-p53 tumor suppressor pathway regulates cell motility by suppression of phosphoinositide 3-kinase and Rac1 GTPase activities. J Biol Chem 2003, 278:14414-14419.

31. Bosco EE, Ni WJ, Wang L, Guo FK, Johnson JF, Zheng Y: Rac1 targeting suppresses p53 deficiency-mediated lymphomagenesis. Blood 2010, 115:3320-3328.

32. Jordan JJ, Menendez D, Inga A, Nourredine M, Bell D, Resnick MA: Noncanonical DNA Motifs as Transactivation Targets by Wild Type and Mutant p53. Plos Genet 2008, 4:e1000104.

33. Menendez D, Inga A, Resnick MA: Estrogen receptor acting in cis enhances WT and mutant p53 transactivation at canonical and noncanonical p53 target sequences. Proc Natl Acad Sci USA 2010, 107:1500-1505.

34. Wang B, Xiao ZW, Ren EC: Redefining the p53 response element. Proc Natl Acad Sci USA 2009, 106:16890-16890.

35. Srougi MC, Burridge K: The Nuclear Guanine Nucleotide Exchange Factors Ect2 and Net1 Regulate RhoB-Mediated Cell Death after DNA Damage. Plos One 2011, 6:e17108.

36. Wang L, Yang L, Debidda M, Witte D, Zheng Y: Cdc42 GTPase-activating protein deficiency promotes genomic instability and premature aginglike phenotypes. Proc Natl Acad Sci USA 2007, 104:1248-1253.

37. Cimoli G, Malacarne D, Ponassi R, Valenti M, Alberti S, Parodi S: Metaanalysis of the role of p53 status in isogenic systems tested for sensitivity to cytotoxic antineoplastic drugs. Biochim Biophys Acta 2004, 1705:103-120.

38. Boulikas T, Vougiouka M: Cisplatin and platinum drugs at the molecular level (review). Oncol Rep 2003, 10:1663-1682.

39. Fraser M, Bai T, Tsang BK: Akt promotes cisplatin resistance in human ovarian cancer cells through inhibition of p53 phosphorylation and nuclear function. Int J Cancer 2008, 122:534-546.

40. Bragado P, Armesilla A, Silva A, Porras A: Apoptosis by cisplatin requires p53 mediated p38 alpha MAPK activation through ROS generation. Apoptosis 2007, 12:1733-1742.

41. Ferraro D, Corso S, Fasano E, Panieri E, Santangelo R, Borrello S, Giordano S, Pani G, Galeotti T: Pro-metastatic signaling by c-Met through RAC-1 and reactive oxygen species (ROS). Oncogene 2006, 25:3689-3698.

42. Ozaki M, Haga S, Zhang HQ, Irani K, Suzuki S: Inhibition of hypoxia/ reoxygenation-induced oxidative stress in HGF-stimulated antiapoptotic signaling: role of P13-K and Akt kinase upon rac1. Cell Death Differ 2003, 10:508-515.

43. Bunz F, Dutriaux A, Lengauer C, Waldman T, Zhou S, Brown JP, Sedivy JM, Kinzler KW, Vogelstein B: Requirement for p53 and p21 to sustain G2 arrest after DNA damage. Science 1998, 282:1497-1501.

44. Li C, Chen H, Ding F, Zhang Y, Luo A, Wang M, Liu Z: A novel p53 target gene, S100A9, induces p53-dependent cellular apoptosis and mediates the p53 apoptosis pathway. Biochem J 2009, 422:363-372.

\section{doi:10.1186/1476-4598-11-54}

Cite this article as: Yang et al:: Interferon regulatory factor 4 binding protein is a novel p53 target gene and suppresses cisplatin-induced apoptosis of breast cancer cells. Molecular Cancer 2012 11:54.

\section{Submit your next manuscript to BioMed Central and take full advantage of:}

- Convenient online submission

- Thorough peer review

- No space constraints or color figure charges

- Immediate publication on acceptance

- Inclusion in PubMed, CAS, Scopus and Google Scholar

- Research which is freely available for redistribution 